\title{
Association between unmet dental needs and school absenteeism because of illness or injury among U.S. school children and adolescents aged 6-17 years, 2011-2012
}

\author{
Israel T. Agaku ${ }^{\mathrm{a}, *}$, Bukola G. Olutola ${ }^{\mathrm{b}}$, Akinyele O. Adisa ${ }^{\mathrm{c}}$, Enihomo M. Obadan ${ }^{\mathrm{d}}$, Constantine I. Vardavas \\ ${ }^{a}$ Department of Social and Behavioral Sciences, Center for Global Tobacco Control, Harvard School of Public Health, Boston, MA, USA ${ }^{\mathrm{b}}$ School of Health Systems and Public Health, \\ University of Pretoria, Pretoria, South Africa \\ c Department of Oral Pathology, College of Medicine, University of Ibadan, Ibadan, Nigeria \\ d Department of Oral Health Policy and Epidemiology, Harvard School of Dental Medicine, Boston, MA, USA
}

Keywords:

Dental caries

Toothache

Absenteeism

Illness

Schools

Unmet dental need

Dental care

Preventive dentistry

\begin{abstract}
A b s t r a c t
Background. We assessed the prevalence of dental disease among U.S. children and adolescents aged 6-17 years, as well as the impact of unmet dental needs on school absenteeism because of illness/injury within the past 12 months.

Methods. Data were from the 2011/2012 National Survey of Children's Health $(n=65,680)$. Unmet dental need was defined as lack of access to appropriate and timely preventive or therapeutic dental healthcare when needed within the past 12 months. The impact of unmet dental needs on school absenteeism was measured using a multivariate generalized linear model with Poisson probability distribution $(p<0.05)$.

Results. Within the past 12 months, $21.8 \%$ (10.8 million) of all U.S. children and adolescents aged 6-17 years had "a toothache, decayed teeth, or unfilled cavities." Of all U.S. children and adolescents aged 6-17 years, 15.8\% (7.8 million) reported any unmet dental need (i.e., preventive and/or therapeutic dental need) within the past 12 months. The mean number of days of school absence because of illness/injury was higher among students with an unmet therapeutic dental need in the presence of a dental condition compared to those reporting no unmet dental need $(\beta=0.25 ; p<0.001)$.

Conclusions. Enhanced and sustained efforts are needed to increase access to dental services among underserved U.S. children and adolescents.
\end{abstract}

\section{Introduction}

Although significant advances have been made in the past several decades in better understanding the etiology, prevention, and treatment of oral diseases, access to timely and appropriate dental care still remains out of the reach of many individuals of low socio-economic status, and disparities in dental care persist (AHRQ 2013; Beltran-Aguilar et al., 2005; US Department of Health and Human Services [US DHHS], 2000). About a third (108 million) of people in the U.S. are not covered by dental insurance, and even those who have dental coverage may have trouble getting care (US DHHS, 2014a). This is further compounded by the short-age of dental care providers in several parts of the U.S. Based on shortage designation criteria developed by the Health Resources and Services Administration (HRSA), as of October 2014, there were 4,968 Dental Health Professional Shortage Areas in the U.S., where 1

\footnotetext{
* Corresponding author at: Center for Global Tobacco Control, Department of Social and Behavioral Sciences, Harvard School of Public Health, 677 Huntington Avenue, Boston MA 02115.

E-mail address: iagaku@post.harvard.edu (I.T. Agaku).
}

dentist serves over 5,000 people (US DHHS, 2014b). HRSA estimates that approximate-ly 7,300 additional dentists are needed to eliminate the current dental Health Professional Shortage Areas designations (US DHHS, 2014c).

Untreated dental diseases may particularly impact negatively among children compared to adults since they are more susceptible to dental caries and generally have lower levels of immunity compared to adults (US DHHS, 2000). Dental caries which is the single most common chronic childhood disease, could lead to infection spread, with potentially lifethreatening outcomes such as jaw osteomyelitis, Ludwig's angina, cavernous sinus thrombosis, and bacterial endocarditis (Shay, 2002; US DHHS, 2000). Dental diseases also impose significant healthcare costs from direct medical expenditures, as well as indirect costs from lost work or school days (Gift et al., 1992; Hollister and Weintraub, 1993; Seirawan et al., 2012). Hence, health objectives related to reducing unmet dental treatment need should be placed in the larger context of prevention. Schoolbased oral health programs and school-based health centers provide opportunities for increasing access to care among low socio-economic status populations through interventions that can reduce unmet dental needs by preventing dental disease. 
Several national objectives have been developed by the U.S. Department of Health and Human Services for reducing the burden of dental diseases and increasing access to preventive and treatment care in dental settings. For example, Healthy People 2020 oral health objective (OH)-2 aims to reduce the prevalence of untreated dental decay among U.S. children and adolescents. Similarly, OH-8 aims to increase the proportion of low income children and adolescents who received any preventive dental service in the past year, to 33.2\% by 2020 (US DHHS, 2014d).

In light of these national objectives, the aims of this study were (1) to assess the prevalence of dental disease and unmet dental need among U.S. children and adolescents aged 6-17 years and (2) to measure the relationship between unmet dental needs and school absenteeism because of illness/injury among school-going children and adolescents aged 6-17 years. Data were obtained from the 2011/2012 National Survey of Children's Health (NSCH).

\section{Methods}

\section{Ethics}

All analyses were performed on de-identified publicly available data; this secondary analysis was deemed exempt from the Harvard School of Public Health, Institutional Review Board (IRB), with IRB protocol number 14-0346.

\section{Data source}

NSCH is an annual survey of non-institutionalized U.S. children aged 0-17 years, using list-assisted random-digit-dial sample of landline telephone numbers, supplemented with an independent random-digit-dial sample of cell phone numbers (Maternal and Child Health Bureau, 2013). The respondents are parents/guardians with knowledge of the health of the sampled child in the household. For the 2011/2012 NSCH, 95,677 questionnaires were completed; yielding an overall response rate of $38.2 \%$ for the landline sample, $15.5 \%$ for the cell phone sample, and $23.0 \%$ for the combined dual-frame sample.

Because school absenteeism was assessed in NSCH only among children and adolescents aged $6-17$ years, we excluded $n=29,997$ children aged $0-5$ years yielding a final analytic sample of $n=65,680$ as our denominator for all prevalence estimates.

\section{Measures}

\section{Oral health status and unmet dental need}

Parents/guardians were asked the following five questions to ascertain their children's oral health status and oral health care access: (1) How would you describe the condition of [CHILD'S NAME] teeth? response options were "excellent," "very good," "good," "fair," or "poor." (2) During the past 12 months, did [CHILD'S NAME] have a toothache, decayed teeth, or unfilled cavities? Response options were "no" or "yes." (3) During the past 12 months, was there any time when [CHILD'S NAME] needed [Dental] health care but it was delayed or not received? Response options were "no" or "yes." (4) During the past 12 months, did [CHILD'S NAME] see a dentist for any kind of dental care, including checkups, dental cleanings, x-rays, or filling cavities? Response options were "no" or "yes." (5) During the past 12 months, how many times did [CHILD'S NAME] see a dentist for preventive dental care, such as checkups and dental cleanings? Response options were re-coded within the survey as "No preventive visits during past 12 months" or "One or more visits during past 12 months."

Based on the responses to these five questions, we constructed two different measures of unmet dental need, as well as an overall measure of any unmet dental need (Lewis et al., 2005; Mayer et al., 2004). These measures were as follows:

1. Lack of access to appropriate and timely therapeutic dental care in the presence of a dental condition (based on questions $1-4)(n=2,923)$. This was defined as a report that a child who needed dental health care within the past 12 months was delayed in receiving it or did not receive it at all, or a report that the child's teeth condition were "fair" or "poor" or the child had "a toothache, decayed teeth, or unfilled cavities" during the past 12 months and yet did not "see a dentist for ... X-rays, or filling cavities" during the past 12 months.

2. Lack of access to preventive dental care (based on question 5$)(n=6,923)$. This was defined as a report that the child did not "see a dentist for preventive dental care, such as checkups and dental cleanings" within the past 12 months.
3. Any unmet dental need was defined as lack of access to preventive dental care and/or appropriate and timely therapeutic dental care in the presence of a dental condition within the past 12 months $(n=8,079)$.

\section{School absenteeism because of illness/injury}

School absenteeism was assessed with the question: "During the past 12 months, about how many days did [CHILD'S NAME] miss school because of illness or injury?" Responses were expressed as discrete data.

Presence of a co-morbidity was defined as a report by a parent/guardian that the sampled child had ever been diagnosed with at least one of 18 listed conditions, and at the time of the survey currently had the condition. The conditions assessed were "A learning disability"; "Attention deficit disorder or attention deficit hyperactive disorder"; "Depression"; "Anxiety problems"; "Behavior or conduct problems"; "Autism, Asperger's disorder, pervasive development disorder, or other autism spectrum disorder"; "Any developmental delay"; "Intellectual disability or mental retardation"; "Cerebral palsy"; "Speech or other language problems"; "Tourette syndrome"; “Asthma"; "Diabetes"; "Epilepsy or seizure disorder"; "Hearing problems"; "Vision problems that cannot be corrected with standard glasses or contact lenses"; "Bone, joint, or muscle problems"; and "A brain injury or concussion."

Data were also collected on whether the child had ever repeated a grade - a variable we used as a proxy for underlying disposition of child towards school attendance or performance. This was defined as a "yes" response to the question "Since starting kindergarten, has [he/she] repeated any grades?"

\section{Socio-demographic characteristics}

We explored several other factors that have been shown to be associated with oral health status and school absenteeism in children and adolescents. These included poverty level ( $\leq 100 \%$ of poverty, also known as living in poverty; or $>100 \%$ of poverty); any health care coverage "including health insurance, prepaid plans such as HMOs, or government plans such as Medicaid" (yes or no); age ( $\leq 9 ; 10-14$; or $\geq 15$ years); gender (male or female); race/ethnicity (non-Hispanic white; non-Hispanic black; Hispanics; or nonHispanic other), and presence of smoker in the household (yes or no). The latter variable was included in the analyses based on previous research documenting a relationship between secondhand smoke exposure in children and increased likelihood of dental caries as well as higher rates of school absenteeism (Levy et al., 2011; Slayton, 2012). In our study, this was defined as a "yes" response to the question "Does anyone smoke inside [CHILD'S NAME]'s home?"

\section{Data analyses}

Data were weighted with the sampling weights provided in the NSCH dataset using the "svyset" function in Stata V12 in order to yield nationally representative estimates.

The prevalence of dental disease and unmet dental needs within the past 12 months was assessed among all U.S. children and adolescents aged $6-17$ years old $(n=65,680)$. Prevalence estimates were calculated overall and further stratified among population subgroups. Statistical significance of differences was tested using the chi-squared statistic. Prevalence estimates with relative standard errors $\geq 30 \%$ were deemed statistically unreliable and are not reported. Sampling weights were used to estimate counts of the number of children with dental disease and unmet dental needs within the past 12 months, as well as the number of school days lost due to illness/ injury.

To measure the relationship between school absenteeism because of illness/ injury and unmet dental needs, we fitted two separate generalized linear models with a Poisson probability distribution family and a log link function, adjusting for age, sex, race/ethnicity, poverty level, health insurance coverage, presence of a comorbidity, and presence of a smoker in the household. Model 1 assessed for the impact of unmet preventive dental care, while model 2 assessed for the impact of unmet therapeutic dental care in the presence of a dental condition. Statistical significance for both models was determined at $p<0.05$. Both models were restricted to children and adolescents aged 6-17 years who were currently enrolled in a regular school - private or public. Hence, of the original denominator of 65,680 children and adolescents aged $6-17$ years used in computing prevalence estimates, we excluded those who were being home-schooled ( $n=1,638)$; those not in school $(n=137)$, and those with unknown status regarding school enrollment $(n=149)$. Homes-chooled students were excluded 
because of difficulty in measuring absenteeism. The denominator for our multivariate analyses was thus $n=63,756$.

\section{Results}

\section{Prevalence of dental disease}

Within the past 12 months, $21.8 \%$ (10.8 million persons) of all U.S. children and adolescents aged 6-17 years were reported to have had "a toothache, decayed teeth, or unfilled cavities," and this varied significantly among all population subgroups except by sex ( $p=0.258$; Table 1$)$. Prevalence was highest among children aged $\leq 9$ years (26.0\%), Hispanics (29.3\%), those with no health coverage (27.8\%), those living at or below $100 \%$ of poverty (31.2\%), those with a co-morbid condition (24.6\%), those that had ever repeated a grade (31.7\%), those with a smoker in the household (26.6\%), and those enrolled in regular school (21.9\%).

At the time of the survey, 8.4\% (4.2 million persons) of all U.S. children and adolescents aged 6-17 years were reported to have teeth that were in a "fair" or "poor" condition, and this varied significantly among all population subgroups except by school enrollment status ( $p=0.778$; Table 1$)$. Prevalence was highest among males (9.3\%), children aged $\leq 9$ years (10.1\%), Hispanics (17.0\%), those with no health coverage (20.6\%), those living at or below $100 \%$ of poverty (18.2\%), those with a co-morbid condition (11.6\%), those that had ever repeated a grade (15.2\%), and those living with a smoker in the household (10.6\%).

\section{Prevalence of unmet dental needs}

Within the past 12 months, 13.7\% (6.7 million persons) of all U.S. children and adolescents aged 6-17 years reported an unmet preventive dental care need, 6.0\% (3.0 million persons) reported an unmet therapeutic dental need in the presence of a dental condition, while $15.8 \%$ (7.8 million persons) reported any unmet dental need (Table 2).

\section{Table 1}

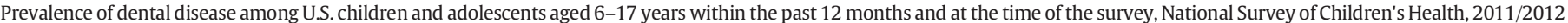
$(n=65,680)$.

\begin{tabular}{|c|c|c|c|c|c|c|}
\hline \multirow[t]{2}{*}{ Characteristics } & \multirow[t]{2}{*}{ Categories } & \multirow{2}{*}{$\begin{array}{l}\text { Sample } \\
N(\%)\end{array}$} & \multicolumn{2}{|c|}{$\begin{array}{l}\text { Report that the child had "a } \\
\text { toothache, decayed teeth, or unfilled } \\
\text { cavities" within the past } 12 \text { months }\end{array}$} & \multicolumn{2}{|c|}{$\begin{array}{l}\text { Report that child's teeth were in a } \\
\text { "fair" or "poor" condition at the time } \\
\text { of the survey }\end{array}$} \\
\hline & & & $\%(95 \% \mathrm{CI})$ & $p$-value ( $\chi^{2}$ test $)$ & $\%(95 \% \mathrm{CI})$ & $p$-value ( $\chi^{2}$ test) \\
\hline Overall & Total & $65,680(100.0)$ & $21.8(21.1-22.6)$ & $\mathrm{n} / \mathrm{a}$ & $8.4(7.9-9.0)$ & $\mathrm{n} / \mathrm{a}$ \\
\hline \multirow[t]{2}{*}{ Sex } & Male & $33,986(51.2)$ & $21.4(20.4-22.5)$ & 0.258 & $9.3(8.5-10.1)$ & 0.002 \\
\hline & Female & $31,607(48.8)$ & $22.3(21.2-23.4)$ & & $7.5(6.8-8.3)$ & \\
\hline \multirow{3}{*}{ Age, years } & $\leq 9$ & $20,371(32.9)$ & $26.0(24.6-27.5)$ & $<0.001$ & $10.1(9.1-11.2)$ & $<0.001$ \\
\hline & $10-14$ & $26,865(41.4)$ & $20.1(19.0-21.3)$ & & $8.1(7.2-8.9)$ & \\
\hline & $\geq 15$ & $18,444(25.7)$ & $19.2(17.8-20.6)$ & & $6.8(5.8-7.8)$ & \\
\hline \multirow{5}{*}{ Race/ethnicity } & White, non-Hispanic & $43,153(52.3)$ & $17.7(16.9-18.5)$ & $<0.001$ & $4.7(4.3-5.2)$ & $<0.001$ \\
\hline & Black, non-Hispanic & $6,177(13.8)$ & $25.7(23.6-27.7)$ & & $8.6(7.2-9.9)$ & \\
\hline & Hispanic & $8,073(21.7)$ & $29.3(27.0-31.6)$ & & $17(15.2-18.9)$ & \\
\hline & Other, non-Hispanic & $6,712(9.5)$ & $21.8(19.5-24.1)$ & & $8.9(7.2-10.5)$ & \\
\hline & Unknown & $1,565(2.7)$ & $22.8(17.8-27.8)$ & & $8.6(5.5-11.7)$ & \\
\hline \multirow[t]{2}{*}{ Any health insurance coverage } & No & $3,118(6.2)$ & $27.8(24.1-31.5)$ & $<0.001$ & $20.6(17.0-24.1)$ & $<0.001$ \\
\hline & Yes & $62,562(93.8)$ & $21.4(20.7-22.2)$ & & $7.6(7.1-8.1)$ & \\
\hline \multirow[t]{2}{*}{ Poverty level } & $\leq 100 \%$ of poverty & $9,135(20.7)$ & $31.2(29.2-33.2)$ & $<0.001$ & $18.2(16.5-20.0)$ & $<0.001$ \\
\hline & $>100 \%$ of poverty & $56,545(79.3)$ & $19.4(18.6-20.2)$ & & $5.9(5.4-6.4)$ & \\
\hline \multirow[t]{2}{*}{ Presence of a co-morbid condition } & No & $46,853(70.9)$ & $20.7(19.8-21.6)$ & $<0.001$ & $7.1(6.5-7.7)$ & $<0.001$ \\
\hline & Yes & $18,822(29.1)$ & $24.6(23.2-26.1)$ & & $11.6(10.5-12.7)$ & \\
\hline \multirow[t]{2}{*}{ Ever repeated a grade } & No & $60,674(90.9)$ & $20.8(20-21.6)$ & $<0.001$ & $7.7(7.2-8.3)$ & $<0.001$ \\
\hline & Yes & $4,847(9.1)$ & $31.7(28.8-34.7)$ & & $15.2(13.0-17.4)$ & \\
\hline \multirow[t]{2}{*}{ Presence of smoker in household } & No & $49,876(75.3)$ & $20.2(19.3-21.1)$ & $<0.001$ & $7.7(7.0-8.3)$ & $<0.001$ \\
\hline & Yes & $15,155(24.7)$ & $26.6(25.0-28.2)$ & & $10.6(9.6-11.7)$ & \\
\hline \multirow[t]{3}{*}{ School enrollment } & Regular school (public or private) & $63,756(97.3)$ & $21.9(21.1-22.6)$ & 0.008 & $8.4(7.9-9.0)$ & 0.778 \\
\hline & Homeschooled & $1,638(2.2)$ & $18.6(14.5-22.6)$ & & $8.8(5.3-12.4)$ & \\
\hline & No school & $137(0.2)$ & $19.4(6.8-32.1)$ & & 9 & \\
\hline
\end{tabular}

Note: Denominator for analyses presented in table was all U.S. children and adolescents aged 6-17 years old. $\mathrm{CI}=\mathrm{confidence} \mathrm{interval;} \mathrm{n} / \mathrm{a}=\mathrm{not}$ applicable

ack of access to preventive dental care within the past 12 months.

b Lack of access to appropriate and timely therapeutic dental care in the presence of a dental condition within the past 12 months.

${ }^{c}$ Lack of access to preventive dental care and/or appropriate and timely therapeutic dental care in the presence of a dental condition within the past 12 months.

${ }^{\mathrm{g}}$ Estimates with relative standard errors $\geq 30 \%$. 
Table 2

Prevalence of unmet dental need among U.S. children and adolescents aged 6-17 years, National Survey of Children's Health, 2011/2012 ( $n=65,680)$.

\begin{tabular}{|c|c|c|c|c|c|c|c|c|}
\hline \multirow[t]{2}{*}{ Characteristics } & \multirow[t]{2}{*}{ Categories } & \multirow{2}{*}{$\begin{array}{l}\text { Sample } \\
N(\%)\end{array}$} & \multicolumn{2}{|c|}{$\begin{array}{l}\text { Unmet preventive dental } \\
\text { need } \\
\text { a }\end{array}$} & \multicolumn{2}{|c|}{$\begin{array}{l}\text { Unmet therapeutic dental } \\
\text { need in the presence of a } \\
\text { dental condition }\end{array}$} & \multicolumn{2}{|c|}{ Any unmet dental need ${ }^{\mathrm{c}}$} \\
\hline & & & $\%(95 \% \mathrm{CI})$ & $\begin{array}{l}p \text {-value } \\
\left(\chi^{2}\right. \\
\text { test })\end{array}$ & $\%(95 \% \mathrm{CI})$ & $\begin{array}{l}p \text {-value } \\
\left(\chi^{2}\right. \\
\text { test })\end{array}$ & $\%(95 \% \mathrm{CI})$ & $\begin{array}{l}p \text {-value } \\
\left(\chi^{2}\right. \\
\text { test })\end{array}$ \\
\hline Overall & Total & $65,680(100.0)$ & $13.7(13.0-14.3)$ & $\mathrm{n} / \mathrm{a}$ & $6.0(5.5-6.4)$ & $\mathrm{n} / \mathrm{a}$ & $15.8(15.1-16.5)$ & $\mathrm{n} / \mathrm{a}$ \\
\hline \multirow[t]{2}{*}{ Sex } & Male & $33,986(51.2)$ & $14.3(13.4-15.3)$ & 0.045 & $6.2(5.6-6.8)$ & 0.350 & $16.1(15.2-17.1)$ & 0.280 \\
\hline & Female & $31,607(48.8)$ & $12.9(12.0-13.9)$ & & $5.8(5.1-6.4)$ & & $15.4(14.4-16.4)$ & \\
\hline \multirow[t]{3}{*}{ Age, years } & $\leq 9$ & $20,371(32.9)$ & $12.3(11.3-13.4)$ & $<0.001$ & $5.5(4.7-6.3)$ & 0.011 & $14.4(13.2-15.5)$ & $<0.001$ \\
\hline & $10-14$ & $26,865(41.4)$ & $12.6(11.6-13.6)$ & & $5.7(5.1-6.3)$ & & $14.5(13.4-15.5)$ & \\
\hline & $\geq 15$ & $18,444(25.7)$ & $17.1(15.6-18.5)$ & & $7.2(6.2-8.2)$ & & $19.7(18.1-21.2)$ & \\
\hline \multirow[t]{5}{*}{ Race/ethnicity } & White, non-Hispanic & $43,153(52.3)$ & $10.1(9.4-10.8)$ & $<0.001$ & $4.5(4.0-4.9)$ & $<0.001$ & $12.1(11.3-12.8)$ & $<0.001$ \\
\hline & Black, non-Hispanic & $6,177(13.8)$ & $17.4(15.6-19.2)$ & & $7.5(6.1-8.8)$ & & $20.4(18.5-22.4)$ & \\
\hline & Hispanic & $8,073(21.7)$ & $18.8(16.8-20.7)$ & & $8.9(7.6-10.3)$ & & $21.0(19.0-23.1)$ & \\
\hline & Other, non-Hispanic & $6,712(9.5)$ & $15.6(13.3-17.9)$ & & $5.8(4.7-7.0)$ & & $17.3(14.9-19.6)$ & \\
\hline & Unknown & $1,565(2.7)$ & $15.2(10.8-19.6)$ & & $4.8(2.3-7.4)$ & & $16.2(11.8-20.7)$ & \\
\hline \multirow{2}{*}{$\begin{array}{l}\text { Any health insurance } \\
\text { coverage }\end{array}$} & No & $3,118(6.2)$ & $46.3(42.3-50.4)$ & $<0.001$ & $25.6(21.9-29.4)$ & $<0.001$ & $51.8(47.7-55.8)$ & $<0.001$ \\
\hline & Yes & $62,562(93.8)$ & $11.5(10.9-12.2)$ & & $4.7(4.3-5.1)$ & & $13.4(12.8-14.1)$ & \\
\hline \multirow[t]{2}{*}{ Poverty level } & $\leq 100 \%$ of poverty & $9,135(20.7)$ & $24.2(22.2-26.1)$ & $<0.001$ & $11.0(9.7-12.3)$ & $<0.001$ & $27.2(25.2-29.2)$ & $<0.001$ \\
\hline & $>100 \%$ of poverty & $56,545(79.3)$ & $10.9(10.3-11.6)$ & & $4.7(4.2-5.1)$ & & $12.8(12.1-13.5)$ & \\
\hline \multirow{2}{*}{$\begin{array}{l}\text { Presence of a co-morbid } \\
\text { condition }\end{array}$} & No & $46,853(70.9)$ & $13.5(12.7-14.3)$ & 0.464 & $5.1(4.6-5.6)$ & $<0.001$ & $15.3(14.4-16.1)$ & 0.023 \\
\hline & Yes & $18,822(29.1)$ & $14.0(12.8-15.2)$ & & $8.2(7.3-9.2)$ & & $17.0(15.7-18.3)$ & \\
\hline \multirow[t]{2}{*}{ Ever repeated a grade } & No & $60,674(90.9)$ & $12.8(12.1-13.5)$ & $<0.001$ & $5.5(5.1-6.0)$ & $<0.001$ & $14.9(14.1-15.6)$ & $<0.001$ \\
\hline & Yes & $4,847(9.1)$ & $22.0(19.2-24.7)$ & & $10.3(8.4-12.3)$ & & $24.4(21.6-27.2)$ & \\
\hline \multirow{2}{*}{$\begin{array}{l}\text { Presence of smoker in } \\
\text { household }\end{array}$} & No & $49,876(75.3)$ & $11.8(11.0-12.5)$ & $<0.001$ & $5.1(4.6-5.6)$ & $<0.001$ & $13.7(12.9-14.5)$ & $<0.001$ \\
\hline & Yes & $15,155(24.7)$ & $19.6(18.2-21.0)$ & & $8.8(7.8-9.7)$ & & $22.4(20.9-23.9)$ & \\
\hline \multirow[t]{3}{*}{ School enrollment } & $\begin{array}{l}\text { Regular school (public or } \\
\text { private) }\end{array}$ & $63,756(97.3)$ & $13.5(12.8-14.1)$ & $<0.001$ & $5.9(5.4-6.3)$ & 0.009 & $15.5(14.8-16.2)$ & $<0.001$ \\
\hline & Homeschooled & $1,638(2.2)$ & $20.7(15.6-25.7)$ & & $10.6(6.1-15.2)$ & & $25.0(19.6-30.3)$ & \\
\hline & No school & $137(0.2)$ & $32.2(14.5-49.9)$ & & 9 & & $32.2(14.5-49.9)$ & \\
\hline
\end{tabular}

Note: Denominator for analyses presented in table was all U.S. children and adolescents aged $6-17$ years old. $\mathrm{CI}=\mathrm{confidence}$ interval; $\mathrm{n} / \mathrm{a}=$ not applicable.

a Lack of access to preventive dental care within the past 12 months.

b Lack of access to appropriate and timely therapeutic dental care in the presence of a dental condition within the past 12 months.

c Lack of access to preventive dental care and/or appropriate and timely therapeutic dental care in the presence of a dental condition within the past 12 months.

g Estimates with relative standard errors $\geq 30 \%$.

lower among Blacks $(\beta=-0.41)$, Hispanics $(\beta=-0.18)$, and other race individuals $(\beta=-0.17)$ when compared to whites (all $p<0.001$ ).

\section{Discussion}

This study demonstrated that about $15.8 \%$ of all U.S. children and adolescents aged 6-17 years reported any unmet dental need within the past 12 months, and this was disproportionately higher among individuals of low socio-economic status, racial/ethnic minorities, those with a co-morbidity, and those living with a smoker. Although an unmet preventive dental care need was not significantly associated with school absenteeism because of illness/injury, having an unmet therapeutic need in the presence of a dental condition was significantly associated with increased school absenteeism because of illness/injury. Indeed, pain and discomfort from dental disease can limit daily functions such as eating, drinking, speech, and sleep (Seirawan et al., 2012; US DHHS, 2000). In addition, other oral conditions that could significantly compromise oro-facial aesthetics and psychosocial wellbeing-including severe tooth discoloration, halitosis, and malocclusion-may result in severe lack of confidence and could adversely affect school attendance and performance (Gift et al., 1992; Seirawan etoalos).

Students who lived with a smoker had higher school absences because of illness/injury compared to those who did not live with a smoker. Secondhand smoke exposure has been associated with impaired cognitive ability in children (Chen et al., 2013; US DHHS, 2006) as well as a plethora of other conditions that could contribute to in-creased lost school days, such as middle ear infections, wheezing, coughing, bronchitis, pneumonia, slow lung development, as well as dental caries (Hanioka et al., 2011; Levy et al., 2011; Slayton, 2012; Tanaka et al., 2009; US DHHS, 2006, 2014a, 2014b, 2014c, 2014d). Living with a smoker might also be a proxy for low socio-economic status since smoking prevalence rates are disproportionately higher among persons of low education or low annual household incomes (Centers for Disease Control and Prevention, 2012).

These findings underscore the need for parents to consider the oral health of their children as being important and inseparable from their general health. Parents should instill good oral health habits and preventive practices in their children early in life, such as those regarding proper tooth brushing, use of feeding bottles/breastfeeding at bedtime, snacking habits, use of fluoride, and implementing smoke-free home rules to prevent secondhand smoke exposure among children-a risk factor for dental caries (Slayton, 2012; Tanaka et al., 2009). In addition, ensuring that children have regular access to preventive dental care from a healthcare professional may help in averting the health and eco-nomic costs of dental disease (US DHHS, 2000).

Dental hygienists and other allied oral health professionals play a significant role in delivering preventive dental care through public health programs that are often targeted to underserved populations (Ohrn, 2004). These programs include school-located screening and cleaning programs, many mobile dentistry activities, and much of the dental care provided in school-based health centers and community health centers (American Dental Hygienists' Association (2013). Enhanced and sustained efforts to expand the coverage of such preventive programs in dental health professional shortage areas may benefit public health and help reduce the burden of unmet dental needs. Other healthcare professionals such as pediatricians can also play a significant role in dental screening and also educate parents on the importance of oral health (Hollister and Weintraub, 1993). This is important considering the fact that more children visit a physician than a dentist annually within the U.S. (American Academy of Pediatrics, 2008a, b). 
Table 3

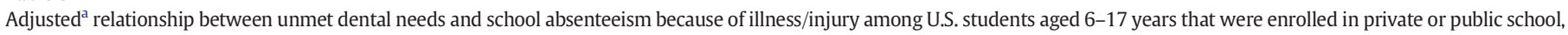
National Survey of Children's Health, 2011/2012 ( $n=63,756)$.

\begin{tabular}{|c|c|c|c|c|c|}
\hline \multirow[t]{2}{*}{ Characteristics } & \multirow[t]{2}{*}{ Categories } & \multicolumn{2}{|l|}{$\begin{array}{l}\text { Model 1: } \\
\text { Unmet preventive dental need }\end{array}$} & \multicolumn{2}{|c|}{$\begin{array}{l}\text { Model 2: } \\
\text { Unmet therapeutic dental need in the } \\
\text { presence of a dental condition }{ }^{c}\end{array}$} \\
\hline & & Adjusted $\beta$ coefficient (95\% CI) & $p$-value & Adjusted $\beta$ coefficient $(95 \% \mathrm{CI}$ ) & $p$-value \\
\hline \multirow[t]{2}{*}{ Unmet dental need } & No (referent) & & & & \\
\hline & Yes & $-0.01(-0.08$ to 0.06$)$ & 0.782 & $0.25(0.16$ to 0.34$)$ & $<0.001$ \\
\hline \multirow[t]{2}{*}{ Sex } & Male (referent) & & & & \\
\hline & Female & $0.11(0.06$ to 0.15$)$ & $<0.001$ & $0.11(0.06$ to 0.15$)$ & $<0.001$ \\
\hline \multirow[t]{3}{*}{ Age, years } & $\leq 9$ (referent) & & & & \\
\hline & $10-14$ & $-0.04(-0.09$ to 0.01$)$ & 0.109 & $-0.04(-0.09$ to 0.01$)$ & 0.107 \\
\hline & $\geq 15$ & $0.11(0.05$ to 0.17$)$ & 0.001 & $0.10(0.04$ to 0.16$)$ & 0.001 \\
\hline \multirow[t]{5}{*}{ Race/ethnicity } & White, non-Hispanic (referent) & & & & \\
\hline & Black, non-Hispanic & $-0.40(-0.48$ to -0.33$)$ & $<0.001$ & $-0.41(-0.48$ to -0.33$)$ & $<0.001$ \\
\hline & Hispanic & $-0.18(-0.26$ to -0.09$)$ & $<0.001$ & $-0.18(-0.27$ to -0.10$)$ & $<0.001$ \\
\hline & Other, non-Hispanic & $-0.16(-0.23$ to -0.1$)$ & $<0.001$ & $-0.17(-0.23$ to -0.10$)$ & $<0.001$ \\
\hline & Unknown & $-0.04(-0.19$ to 0.11$)$ & 0.633 & $-0.03(-0.18$ to 0.12$)$ & 0.659 \\
\hline \multirow[t]{2}{*}{ Any health insurance coverage } & No (referent) & & & & \\
\hline & Yes & $0.18(0.09$ to 0.28$)$ & $<0.001$ & $0.24(0.15$ to 0.33$)$ & $<0.001$ \\
\hline \multirow[t]{2}{*}{ Poverty level } & $\leq 100 \%$ of poverty (referent) & & & & \\
\hline & $>100 \%$ of poverty & $-0.08(-0.14$ to -0.01$)$ & 0.017 & $-0.06(-0.12$ to 0.01$)$ & 0.051 \\
\hline \multirow[t]{2}{*}{ Presence of a co-morbid condition } & No (referent) & & & & \\
\hline & Yes & $0.60(0.55$ to 0.65$)$ & $<0.001$ & $0.59(0.54$ to 0.64$)$ & $<0.001$ \\
\hline \multirow[t]{2}{*}{ Ever repeated a grade } & No (referent) & & & & \\
\hline & Yes & $0.10(0.02$ to 0.18$)$ & 0.013 & 0.09 (0.02 to 0.17$)$ & 0.020 \\
\hline \multirow[t]{2}{*}{ Presence of smoker in household } & No (referent) & & & & \\
\hline & Yes & $0.22(0.17$ to 0.27$)$ & $<0.001$ & $0.21(0.16$ to 0.26$)$ & $<0.001$ \\
\hline
\end{tabular}

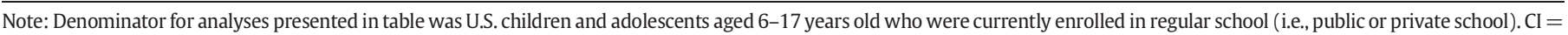

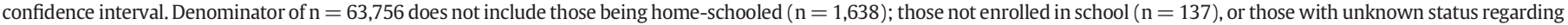
school enrollment $(n=149)$.

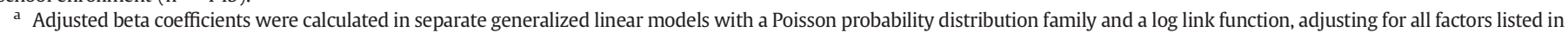
table.

b Lack of access to preventive dental care within the past 12 months.

c Lack of access to appropriate and timely therapeutic dental care in the presence of a dental condition within the past 12 months.

This study has some limitations. First, the framing of the question assessing children's access to preventive dental care (i.e., "During the past 12 months, how many times did [CHILD'S NAME] see a dentist for preventive dental care, such as checkups and dental cleanings?") may have resulted in underestimates. This is because a substantial amount of preventive dental care for children does not involve seeing a "dentist," and this question would miss that entire paradigm of care provided by dental hygienists and other allied oral health professionals in alternative settings (American Dental Hygienists' Association, 2013). Second, since children were not actually examined by a dental professional in the survey, data are not available to fully characterize unmet dental needs in relation to indices such as decayed, missing, and filled teeth (DMFT). It may be that the children with unmet dental needs had a high decayed (D) component of DMFT and low missing (M) or filled $(F)$ teeth, which might be suggestive of a low care index while those children reporting no unmet dental needs might have had a high care index with high missing $(\mathrm{M})$ or filled teeth $(\mathrm{F})$ and a low decayed (D) component of DMFT. Third, the parents or adult caretakers who provided responses in the survey might have had limited understanding of the full spectrum of dental needs of the sampled child, and this may have influenced the accuracy of the responses. For example, not reporting an unmet dental need may not necessarily mean that all dental needs had been met. Finally, the cross-sectional nature of the data precludes causal inferences and only associations can be inferred. Despite these limitations, our findings underscore the need for intensified efforts to ensure improved access to preventive, interceptive, and therapeutic dental care among children.

\section{Conclusion}

Analyses of cross-sectional data among U.S. children and adolescents aged $6-17$ years indicated that $15.8 \%$ had any unmet dental need within the past 12 months. Having an unmet therapeutic dental need in the presence of a dental condition was associated with increased likelihood of school absenteeism because of illness/injury. Enhanced and sustained efforts are needed to extend preventive health coverage among underserved populations in order to reduce unmet dental need among U.S. children and adolescents.

\section{Funding}

There was no source of direct or indirect funding for the reported research.

\section{Declaration of interest}

The authors have no competing interests to report.

\section{Acknowledgments}

This research received no specific grant from any funding agency in the public, commercial, or not-for-profit sectors. Dr. Israel Agaku initiated the reported research while affiliated with the Center for Global Tobacco Control at Harvard University. He is currently affiliated with the Centers for Disease Control and Prevention's Office on Smoking and Health. The research in this report was completed and submitted outside of the official duties of his current position and does not reflect the official policies or positions of the Centers for Disease Control and Prevention.

\section{References}

AHRQ 2013. Annual Highlights and Report. Agency for Healthcare Research and Quality, Rockville, MD (July, http://www.ahrq.gov/news/newsroom/highlights/index.html). American Academy of Pediatrics, 2008a. Profile of pediatric visits: Tables 9-10 [based on 2000-2005 Medical Expenditure Panel Survey and 2000-2004 National Ambulatory 
Medical Care Survey]. Updated June 2008. Available at, http://practice.aap.org/public/ ProfileOfPediatricVisits.pdf (Accessed July 31, 2008).

American Academy of Pediatrics, 2008b. Section on Pediatric Dentistry and Oral Health. (2008). Preventive oral health intervention for pediatricians. Pediatrics 122 (6), 1387-1394. http://dx.doi.org/10.1542/peds.2008-2577 (http://dx.doi.org/10.1542/ peds.2008-2577).

American Dental Hygienists' Association, 2013. Facts about the Dental Hygiene Workforce in the United States. Facts about the Dental Hygiene Workforce in the United States, Available at. http://www.adha.org/resources-docs/75118_Facts_About_the_Dental_ Hygiene_Workforce.pdf.

Beltran-Aguilar, E.D., Barker, L.K., Canto, M.T., et al., 2005. Surveillance for dental caries, dental sealants, tooth retention, edentulism, and enamel fluorosis-United States, 1988-1994 and 1999-2002. Morb. Mortal. Wkly Rep. 54 (3), 1-43 (Surveillance Summaries (Washington, D.C.: 2002)).

Centers for Disease Control and Prevention (CDC), 2012. Current cigarette smoking among adults-United States, 2011. MMWR Morb. Mortal. Wkly Rep. 61 (44), 889-894.

Chen, R., Clifford, A., Lang, L., Anstey, K.J., 2013. Is exposure to secondhand smoke

assoated with cognitive parameters of children and adolescents?-A systematic literature review. Ann. Epidemiol. 23 (10), 652-661. http://dx.doi.org/10.1016/j.annepidem. 2013.07.001 (http://dx.doi.org/10.1016/j.annepidem.2013.07.001).

Gift, H.C., Reisine, S.T., Larach, D.C., 1992. The social impact of dental problems and visits. Am. J. Public Health 82 (12), 1663-1668.

Hanioka, T., Ojima, M., Tanaka, K., Yamamoto, M., 2011. Does secondhand smoke affect the development of dental caries in children? A systematic review. Int. J. Environ. Res. Public Health 8 (5), 1503-1519. http://dx.doi.org/10.3390/ijerph8051503 (http://dx.doi.org/10.3390/ijerph8051503).

Hollister, M.C., Weintraub, J.A., 1993. The association of oral status with systemic health, quality of life, and economic productivity. J. Dent. Educ. 57 (12), 901-912.

Levy, D.E., Winickoff, J.P., Rigotti, N.A., 2011. School absenteeism among children living with smokers. Pediatrics 128 (4), 650-656. http://dx.doi.org/10.1542/peds.20111067 (http://dx.doi.org/10.1542/peds.2011-1067).

Lewis, C., Robertson, A.S., Phelps, S., 2005. Unmet dental care needs among children with special health care needs: implications for the medical home. Pediatrics 116 (3), e426-e431. http://dx.doi.org/10.1542/peds. 2005-0390.

Maternal and Child Health Bureau, National Center for Health Statistics, 2013. 2011/12 National Survey of Children's Health. NSCH, Stata Indicator Data Set prepared by the Data Resource Center for Child and Adolescent Health. Child and Adolescent Health Measurement Initiative (www.childhealthdata.org <http://www.childhealthdata.org/>)

Mayer, M.L., Skinner, A.C., Slifkin, R.T., 2004. Unmet need for routine and specialty care: data from the national survey of children with special health care needs. Pediatrics 113 (2), e109-e115.
Ohrn, K., 2004. The role of dental hygienists in oral health prevention. Oral Health Prev. Dent. 2 (Suppl. 1), 277-281.

Seirawan, H., Faust, S., Mulligan, R., 2012. The impact of oral health on the academic

per-formance of disadvantaged children. Am. J. Public Health 102 (9), 1729-1734. http:// dx.doi.org/10.2105/AJPH.2011.300478 (http://dx.doi.org/10.2105/AJPH.2011. 300478).

Shay, K., 2002. Infectious complications of dental and periodontal diseases in the elderly population. Clin. Infect. Dis. Off. Publ. Infect. Dis. Soc. Am. 34 (9), 1215-1223. http://dx.doi.org/10.1086/339865.

Slayton, R.L., 2012. Exposure to secondhand smoke may cause dental caries in children. J. Evid.-Based Dent. Pract. 12 (1), 8-9. http://dx.doi.org/10.1016/j.jebdp.2011.12.004 (http://dx.doi.org/10.1016/j.jebdp.2011.12.004).

Tanaka, K., Miyake, Y., Sasaki, S., 2009. The effect of maternal smoking during pregnancy and postnatal household smoking on dental caries in young children. J. Pediatr. 155 (3), 410-415. http://dx.doi.org/10.1016/j.jpeds.2009.03.032 (http://dx.doi.org/10. 1016/j.jpeds.2009.03.032).

US Department of Health and Human Services, 2000. Oral Health in America: A Report of the Surgeon General-Executive Summary. US Department of Health and Human Ser-vices, National Institute of Dental and Craniofacial Research, National Institutes of Health, Rockville, MD.

US Department of Health and Human Services, 2006. The Health Consequences of Involuntary Exposure to Tobacco Smoke: A Report of the Surgeon General. US Department of Health and Human Services, CDC, Atlanta, GA (Available at http://www. surgeongeneral.gov/library/secondhandsmoke/report/fullreport.pdf. Accessed October 30, 2012).

US Department of Health and Human Services, 2014a. Health Resources and Services Administration. Oral Health (http://www.hrsa.gov/publichealth/clinical/oralhealth/. Accessed July 31, 2014).

US Department of Health and Human Services, 2014b. Health Resources and Services Administration. Shortage Areas (http://datawarehouse.hrsa.gov/topics/shortageAreas. aspx. Accessed November 8, 2014).

US Department of Health and Human Services, 2014c. Health Resources and Services Administration. Shortage Designation: Health Professional Shortage Areas \& Medically Underserved Areas/Populations. Available at, http://www.hrsa.gov/shortage/ (Accessed November 8, 2014).

US Department of Health and Human Services, 2014d. Healthy People 2020. Oral Health (Available at http://www.healthypeople.gov/2020/LHI/oralHealth.aspx. Accessed January 12, 2014). 